\title{
Urethanes and polyurethanes from suberin 2: synthesis and characterization
}

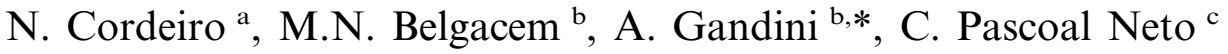 \\ a Department of Chemistry, University of Madeira, 9000 Funchal, Portugal \\ b Matériaux Polymères, École Française de Papeterie et des Industries Graphiques (INPG), BP 65, \\ 38402 St. Martin d'Hères, France \\ c Department of Chemistry, University of Aveiro, 3810 Aveiro, Portugal
}

Received 8 May 1998; accepted 22 October 1998

\begin{abstract}
Polyurethanes based on suberin from cork of Quercus suber L. and conventional isocyanate monomers were prepared and fully characterized in terms of both structure (FTIR and ${ }^{1} \mathrm{H}$ NMR spectroscopy) and thermal properties (differential scanning calorimetry and thermogravimetric analysis). Two fractions were systematically isolated, namely (i) methylene-chloride soluble products, which corresponded to linear and branched macromolecules and (ii) methylene-chloride insoluble products, representing the crosslinked material. The structures of these polymers were regular and no appreciable side reactions were detected. DSC analyses provided information about the glass transition temperature of both fractions and this parameter was correlated with the stiffness of the isocyanate used. The TGA of these polyurethanes showed that they started to degrade at about $175^{\circ} \mathrm{C}$ and that the residue at $400^{\circ} \mathrm{C}$ was around $50 \%$. The highest amounts of insoluble fractions, as well as the highest $T_{\mathrm{g}} \mathrm{s}$, were reached when an initial $[\mathrm{NCO}] /[\mathrm{OH}]$ of unity was used. (C) 1999 Elsevier Science B.V. All rights reserved.
\end{abstract}

Keywords: Suberin; Cork; Quercus suber L.; Polyurethanes; Thermal properties; Glass transition

\section{Introduction}

The chemical exploitation of renewable resources, such as the vegetal biomass, constitutes a promising and indeed auspicious alternative to the use of non-renewable fossil resources and repre-

\footnotetext{
* Corresponding author.
}

sents a rich and varied source of polymers, oligomers and monomers (Gandini, 1992). In the last several years, we have been engaged in a collaboration aimed at finding new rational ways of employing wastes from the cork industry, which represent $20-25 \%$ by weight of the total consumption of that natural material, whose production exceeds 150000 tons per year in Portugal. 
These rejects have a low granulometry and are presently burned to recover energy, regardless of the fact that they can be a source of useful chemicals. In fact, cork is made up of $40-50 \%$ suberin, $19-22 \%$ lignin, $12-20 \%$ polysaccharides and $13-16 \%$ extractive components (Guillemonat, 1960; Carvalho, 1968; Holloway, 1972; Pereira, 1984; Marques and Pereira, 1987; Pereira, 1988).

We have previously shown that alkaline methanolysis appears to be the most efficient way of isolating suberin, i.e. the major and most interesting component, from cork. The chemical structure of the resulting mixture of products was established by FTIR, RMN and GC-MS and showed that the dominant features were long aliphatic sequences with methyl ester end-groups (arising from the solvolysis of the in situ ester groups) and secondary hydroxy functions along the chains (Cordeiro et al., 1998a). The number average molecular weight of these oligomeric fragments was about 800 , their hydroxy index about 160 and their average functionality $2.3 \mathrm{OH}$ per molecule (Cordeiro et al., 1998a).

These OH-rich molecules constitute a logical starting material to elaborate polyurethanes by polycondensation reactions with multifunctional isocyanates. To the best of our knowledge no previous work on the use of suberin as a macromonomer was published before our investigation begun, with the exception of a paper by Yanes et al. (Yanes and Sanchez, 1961) concerning the preparation of polyesters based on phelogenic acid, which however represents only $0.3 \%$ of the suberin constituents.

We have already studied the surface energy of cork powder (Cordeiro et al., 1995) in order to investigate the possibility of its use as a filler in polymeric matrices. We have also determined the surface properties of suberin (Cordeiro et al., 1997a), with the aim of assessing its possible role as a surface modifier in printing ink formulations.

This paper follows a previous piece of research on the kinetics of the condensation reactions between suberin and mono- as well as di-functional isocyanates to give urethanes and polyurethanes (Cordeiro et al., 1997b). We carried out that preliminary study in order to establish the reactivity of suberin toward isocyanates and determine the kinetic features of the formation of the urethane function. We showed that the reactions followed a classical second-order behaviour up to high conversion and that the reactivity of different isocyanates followed patterns which could be readily rationalized in terms of steric hindrance and electronic factors.

The present paper reports the pursuit of that investigation, concentrating on the syntheses, structure and properties of this new family of suberin-based polyurethanes.

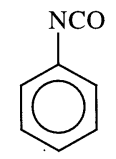

PHI, F = 1

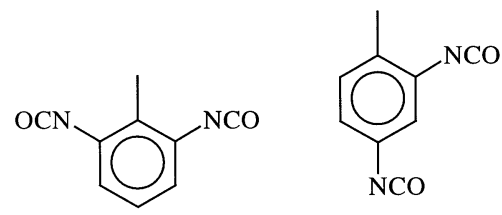

2,6-TDI, $\mathrm{F}=2$

2,4-TDI, $\mathrm{F}=2$

(TDI-II is a 80:20 w/w mixture of 2,4- and 2,6-TDI)<smiles>O=CNc1ccc(Cc2ccc(N=O)cc2)cc1</smiles>

MDI-2.0, F = 2

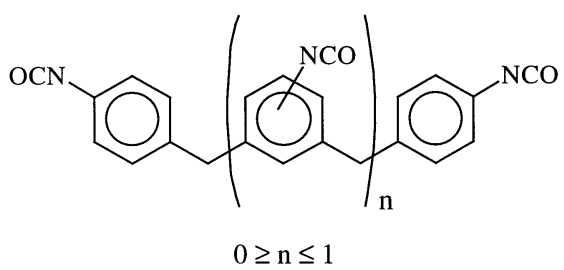

MDI-2.7, $\mathrm{F}=\mathbf{2 . 7}$

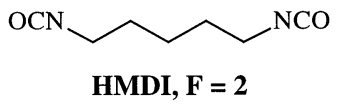

Scheme 1. Chemical structures and functionality $(\mathrm{F})$ of the isocyanates used in this work. 


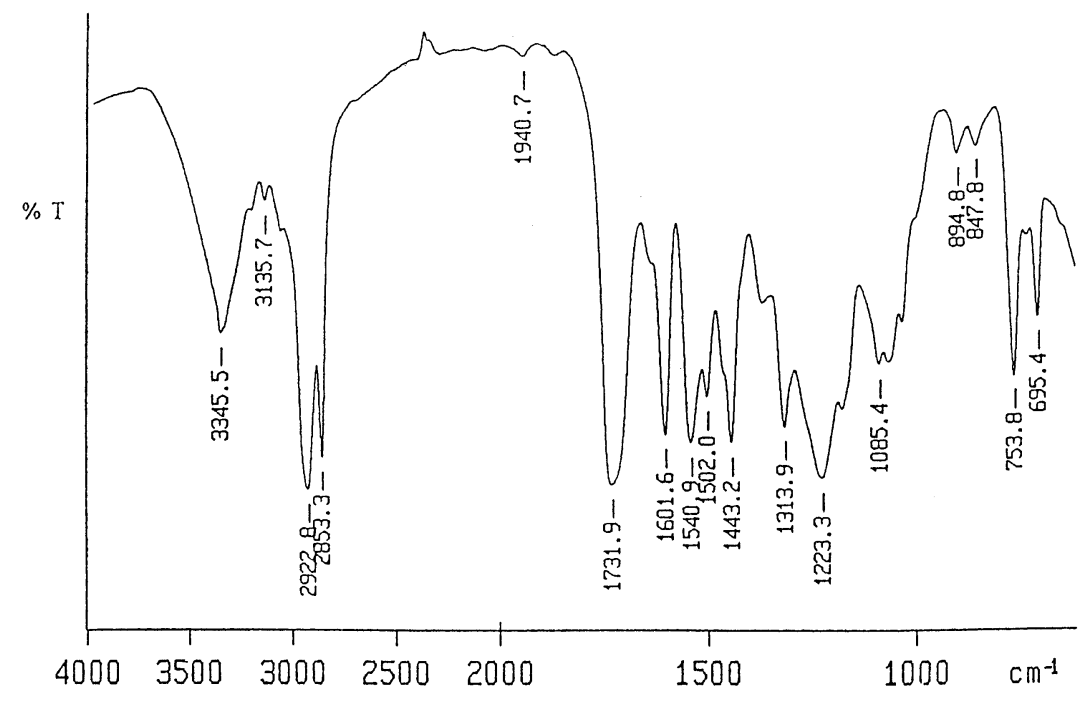

Fig. 1. FTIR spectrum of suberin-phenyl-isocyanate.

\section{Experimental}

The suberin used, was obtained from high quality reproduction cork of Quercus suber L., kindly supplied by the Champcork Company. The procedure adopted, described in detail elsewhere (Cordeiro et al., 1998a), consisted in the sequential extraction of cork powder with dichloromethane, ethanol and water, followed by the hydrolysis of the residue by a methanolic $\mathrm{NaOH}$ solution. Suberin was then recovered by extraction with chloroform, the solvent removed by vacuum distillation and the residue, called hereafter suberin, thoroughly characterized (Cordeiro et al., 1997a,b, 1998a,b).

The polyurethane syntheses were carried out by mixing a $0.2 \mathrm{M}$ solution of suberin in dry tetrahydrofuran (THF) with the given isocyanate in the presence of $10^{-2} \mathrm{M}$ of dibutyltin dilaurate as a catalyst, at $70 \pm 1{ }^{\circ} \mathrm{C}$ and under a stream of dry nitrogen. The reaction was monitored by FTIR spectroscopy by following the progressive decrease in the absorption of the NCO band around $2250 \mathrm{~cm}^{-1}$ and stopped by cooling either just after its disappearance (when $[\mathrm{NCO}]_{0} /[\mathrm{OH}]_{0} \leq 1$ ), or once its intensity had reached a constant value (when an excess of isocyanate was used).
At the end of the reactions between the model monofunctional phenyl isocyanate and suberin, the solvent was evaporated and the corresponding urethanes recovered by precipitation in diethyl ether. The use of isocyanates with a functionality of two or higher, produced a mixture of branched and crosslinked polyurethanes. At the end of these polycondensation reactions, the solvent was removed under vacuum and the ensuing products extracted in a soxhlet apparatus with methylene chloride for $12 \mathrm{~h}$. Two fractions were obtained: a soluble product corresponding to branched structures and an insoluble one representing the crosslinked polymer.

The isocyanates, solvents and catalyst used in this work were commercial products of the highest purity available supplied by Aldrich, except for the industrial MDI with an average molecular functionality of 2.7 (from Shell France) and the mixture of $80: 20(\mathrm{w} / \mathrm{w})$ of 2,4-TDI and 2,6-TDI (TDI-II) (from Rhône Poulenc, Lyon). Scheme 1 gives the chemical structures and the functionality of all the isocyanates used in this study.

The FTIR spectra were recorded on a PerkinElmer Paragon 1000 spectrophotometer, whereas the ${ }^{1} \mathrm{H}$ NMR spectra were taken with a Brucker 


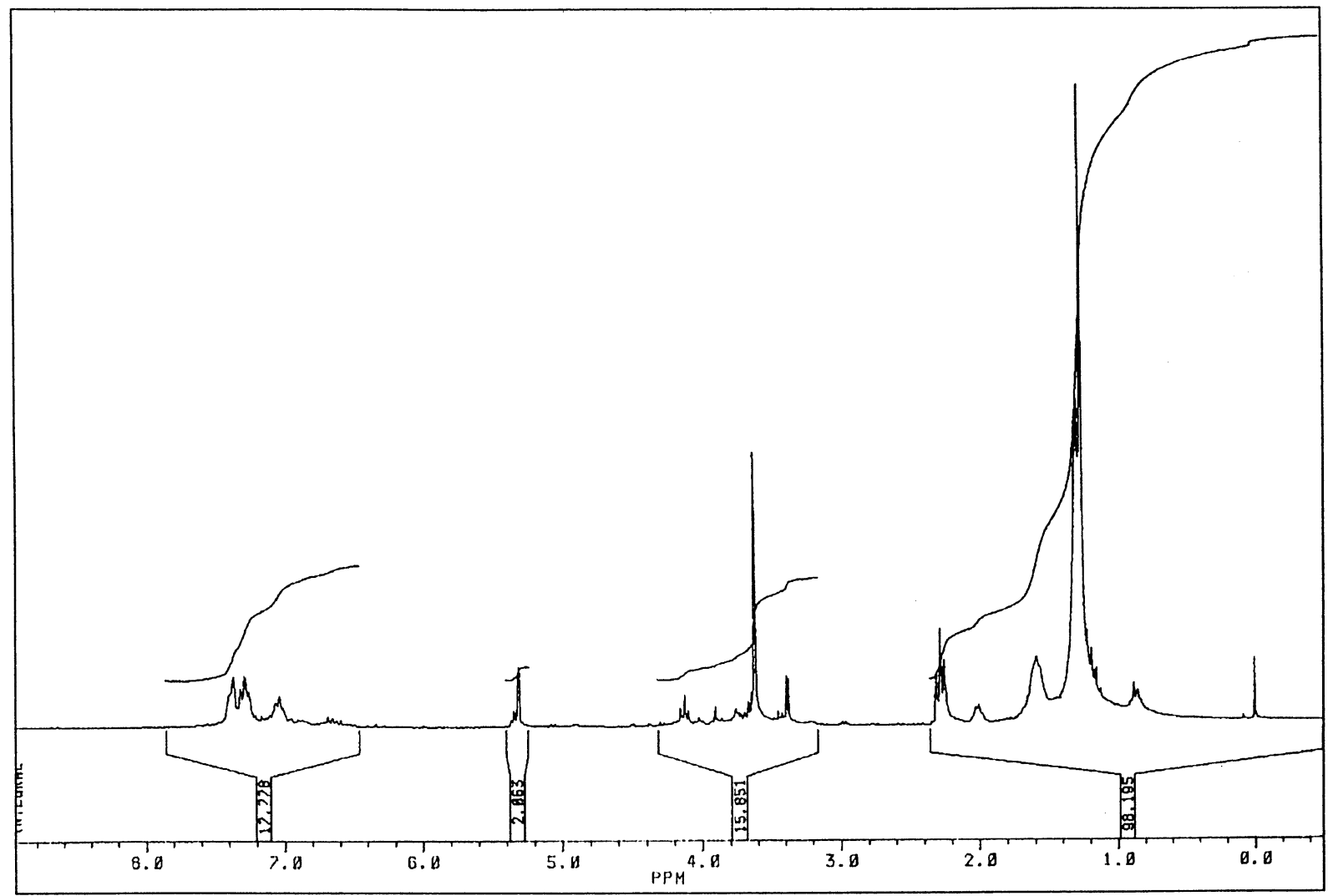

Fig. 2. ${ }^{1} \mathrm{H}$ NMR spectrum of suberin-phenyl-isocyanate.

AMX-300 instrument. Deuterated chloroform was used as a solvent for the soluble fractions of the suberin-based polyurethanes and tetramethylsilane (TMS) as the internal standard. The chemical shifts $(\delta)$ are given in ppm downfield from TMS.

DSC and TGA were carried out with a Setaram DSC 92 analyzer. For DSC studies ca. $10 \mathrm{mg}$ of sample were loaded into aluminum capsules, which were then annealed and carefully placed in the DSC oven maintained under a stream of dry nitrogen. Cooling at $15^{\circ} \mathrm{C} / \mathrm{min}$ was insured by cold nitrogen vapour and heating between -150 and $+150^{\circ} \mathrm{C}$ occurred at a rate of $10^{\circ} \mathrm{C} / \mathrm{min}$. For TGA analyses ca. $20 \mathrm{mg}$ of sample were heated under a stream of nitrogen at a rate of $10^{\circ} \mathrm{C} / \mathrm{min}$.

\section{Results and discussion}

\subsection{Reactions with phenyl isocyanate}

Before starting the synthesis of polyurethanes, we carried out the reaction between suberin and phenyl isocyanate in stoichiometric conditions in order to obtain a totally soluble product, which could be easily characterized in terms of structural regularity. The suberin-phenyl-urethanes thus obtained with a yield of about $90 \%$ were viscous materials. The FTIR spectrum, shown in Fig. 1, displays the presence of the typical peaks arising from the urethanes moiety, i.e. $\mathrm{NH}, \mathrm{C}=\mathrm{O}$ and $\mathrm{O}=\mathrm{C}-\mathrm{O}$ at 3345,1732 and $1223 \mathrm{~cm}^{-1}$, respectively. The absence of a peak or shoulder arising 
Table 1

Amounts of the soluble and insoluble fractions and $T_{\mathrm{g}}$ of the insoluble fractions of polyurethanes prepared by the reaction between suberin and MDI-2.0 with various $[\mathrm{NCO}]_{0} /[\mathrm{OH}]_{0}$ ratios

\begin{tabular}{llll}
\hline$[\mathrm{NCO}]_{0} /[\mathrm{OH}]_{0}$ & Soluble fraction $(\%)$ & Insoluble fraction $(\%)$ & $T_{\mathrm{g}}\left({ }^{\circ} \mathrm{C}\right)$ \\
\hline 0.5 & 78.9 & 20.1 & 58 \\
0.7 & 50.7 & 42.1 & 76 \\
0.8 & 43.1 & 55.6 & 88 \\
0.9 & 36.8 & 62.0 & 91 \\
1.0 & 29.0 & 70.3 & 98 \\
1.2 & 55.2 & 44.0 & 68 \\
1.3 & 66.4 & 33.1 & 50
\end{tabular}

from the $\mathrm{OH}$ groups of suberin (Cordeiro et al., 1998a) at $3465 \mathrm{~cm}^{-1}$, proved that all the hydroxy groups of suberin had indeed reacted. As shown in Fig. 2, the ${ }^{1} \mathrm{H}$ NMR spectrum gave six groups of resonances, respectively, in the regions: (i) $1.2-$ $1.8 \mathrm{ppm}$, corresponding to the aliphatic methylene protons of suberin; (ii) 1.8-2.4 ppm, representing the methylene protons linked to carbonyl moieties of ester groups; (iii) 3.4-3.8 ppm, corresponding to methoxy protons; (iv) $3.8-4.4$, attributed to aliphatic protons attached to carbons bearing the urethane functions; (v) $5.3 \mathrm{ppm}$, corresponding to the modest presence of alkenyl protons in the suberin structure; and (vi) 6.7-7.4 ppm, corresponding to the aromatic protons from the phenyl urethane moieties.

The DSC thermogram of the phenyl-suberinurethane showed an endothermic peak centered at $42^{\circ} \mathrm{C}$, representing the melting point of the crystalline fraction of the product.

The synthesis and the characterization of this model compound proved that suberin behaves in a straightforward manner in the context of its use as a polyol in polyurethane formulations and opened the way to the preparation of a new family of suberin-based polymeric materials.

\subsection{Reactions with multifunctional isocyanates}

The influence of the initial $[\mathrm{NCO}] /[\mathrm{OH}]$ ratio on the yield of the insoluble fraction arising from the reaction between suberin and MDI-2.0 was studied in detail. Table 1 shows that, as expected for a non-linear polycondensation reaction, the highest proportion of crosslinked material was reached with the stoichiometric condition $([\mathrm{NCO}] /[\mathrm{OH}=$ 1). The fact that the network did not involve $100 \%$ of the product is attributed to the presence of suberin molecules bearing only one or two $\mathrm{OH}$ groups. The FTIR of both the soluble and insoluble fractions of these polyurethanes showed the presence of the expected urethane functions, namely: $\mathrm{NH}, \mathrm{C}=\mathrm{O}$ and $\mathrm{O}=\mathrm{C}-\mathrm{O}$ at 3343,1736 and $1221 \mathrm{~cm}^{-1}$, respectively. The absence of peaks arising from either $\mathrm{OH}$ or $\mathrm{NCO}$ groups suggested that complete reaction had been achieved. For polyurethanes obtained using an excess of MDI-2.0, a weak residual NCO band around $2250 \mathrm{~cm}^{-1}$ was detected. Fig. 3 shows the FTIR spectra of both soluble and insoluble fractions of the suberin-MDI-2.0 polyurethane obtained under stoichiometric conditions.

The ${ }^{1} \mathrm{H}$ NMR spectra of these polyurethanes showed again six groups of resonances, respectively, in the regions: (i) $1.2-1.8 \mathrm{ppm}$, which corresponded to the aliphatic protons of suberin; (ii) $1.8-2.4 \mathrm{ppm}$, which were attributed to methylene protons linked to the carbonyl moieties of the ester groups of suberin; (iii) $3.4-3.8 \mathrm{ppm}$, which were assigned to the methoxy groups of suberin and the two protons of the methylene group bridging the two phenyl moieties of MDI2.0; (iv) 3.8-4.4, which represented protons attached to carbons bearing the urethane functions; (v) $5.3 \mathrm{ppm}$, which corresponded to the modest presence of alkenyl protons in the suberin structure; and (vi) 6.6-7.9 ppm, corresponding to the aromatic protons of the urethane moiety from MDI-2.0. Fig. 4 gives the ${ }^{1} \mathrm{H}$ NMR spectrum of 


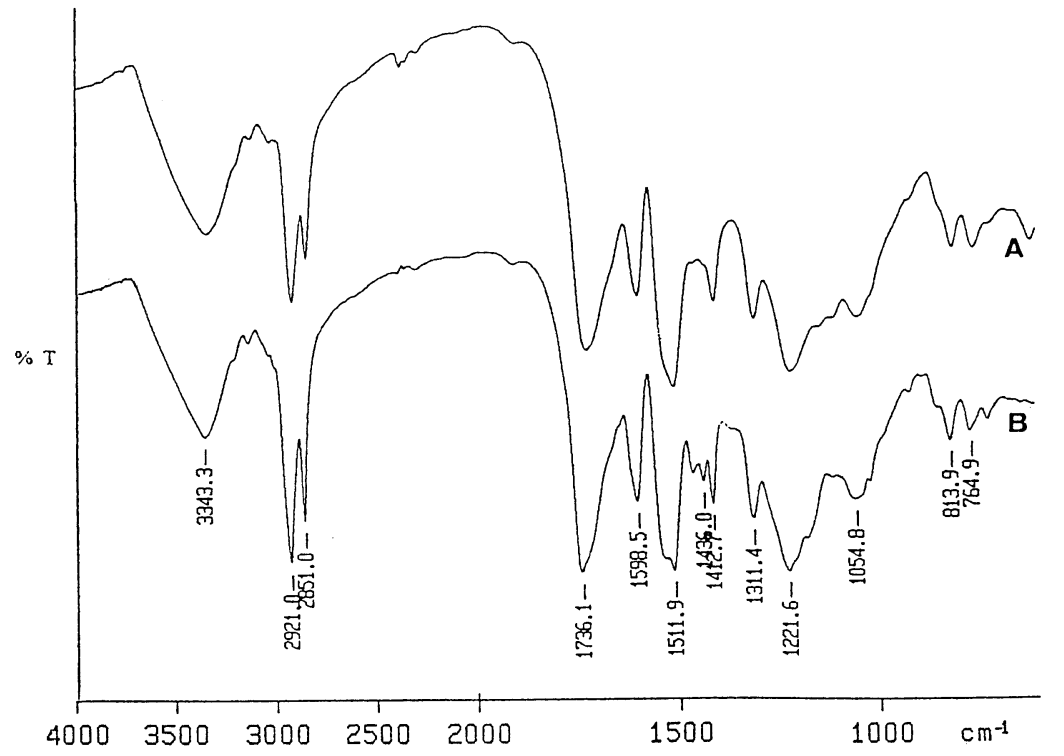

Fig. 3. FTIR spectra of a polyurethane prepared with suberin and MDI-2.0 with $[\mathrm{NCO}]_{0} /[\mathrm{OH}]_{0}=1 ;(\mathrm{A})$ insoluble fraction; $(\mathrm{B})$ soluble fraction.

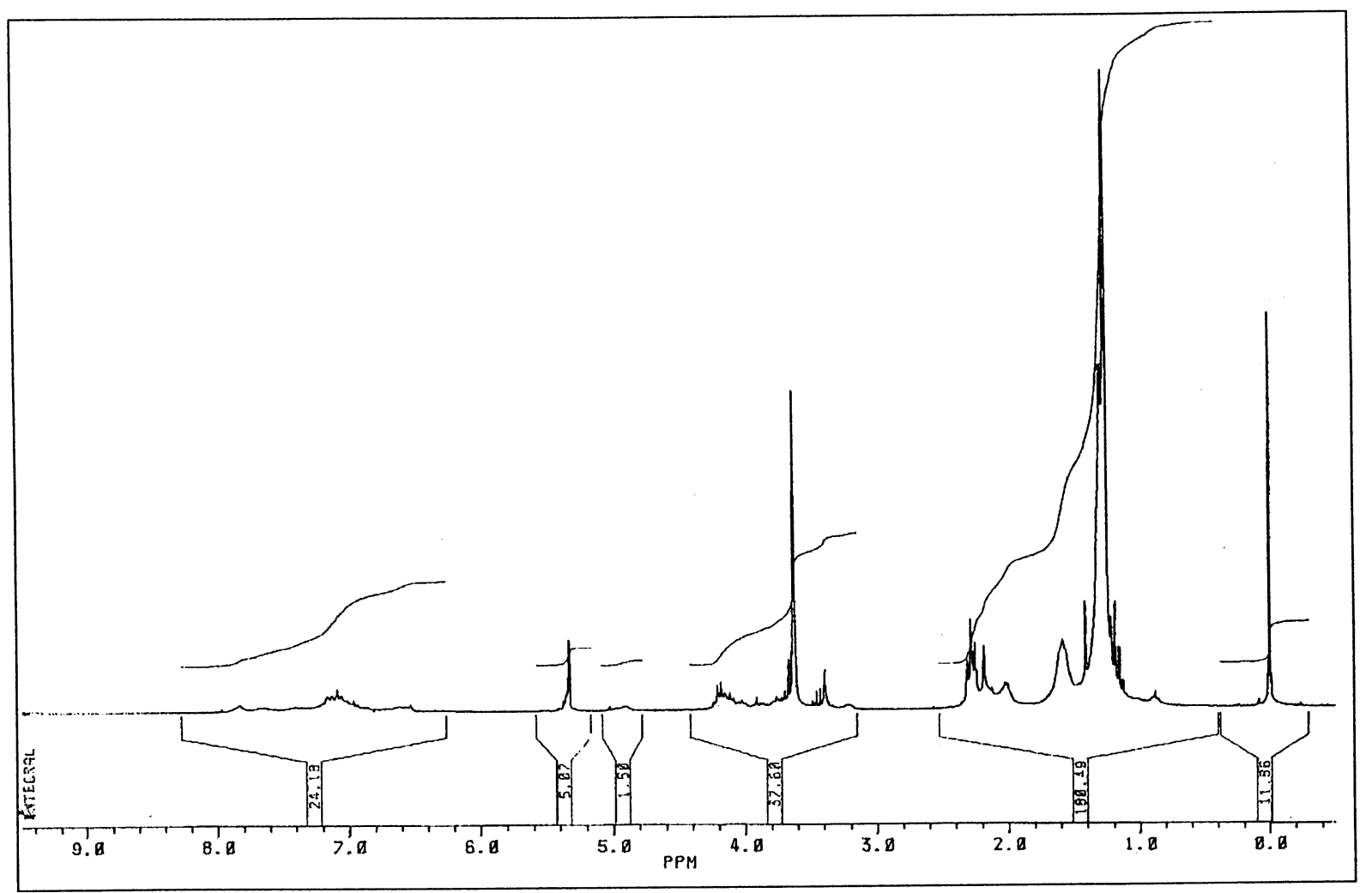

Fig. 4. ${ }^{1} \mathrm{H}$ NMR spectrum of the soluble fraction of the suberin-MDI-2.0 polyurethane prepared with $[\mathrm{NCO}]_{0} /[\mathrm{OH}]_{0}=1$. 


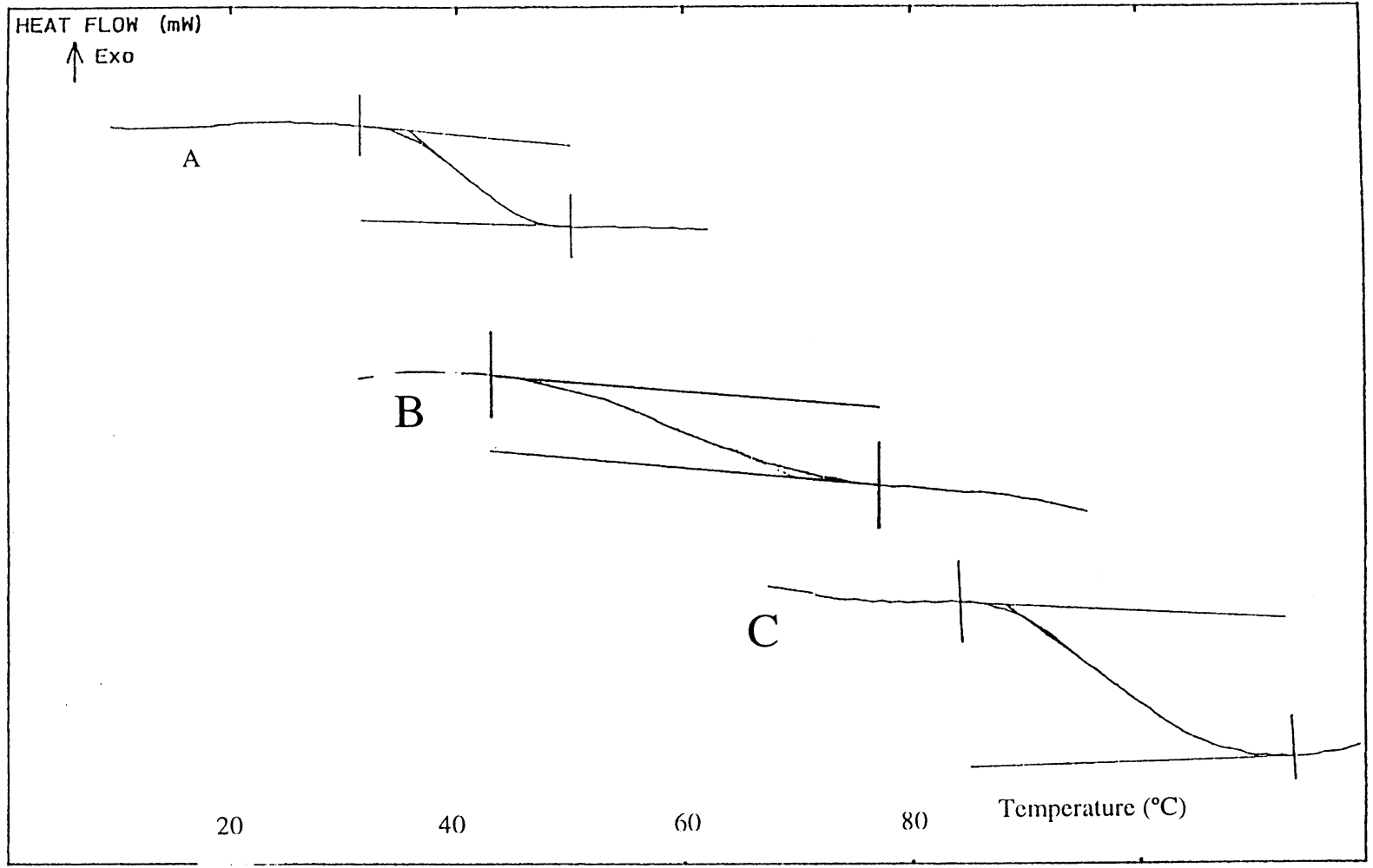

Fig. 5. DSC thermograms of the suberin-MDI-2.0 polyurethane prepared with $[\mathrm{NCO}]_{0} /[\mathrm{OH}]_{0}=1$; (A) soluble fraction; $(\mathrm{B})$ before extraction; (C) insoluble fraction.

the soluble fraction of a suberin-MDI-2.0 polyurethane obtained with $[\mathrm{NCO}]_{0} /[\mathrm{OH}]_{0}=1$.

The DSC analyses of this series of polyurethanes, prepared with seven different $[\mathrm{NCO}] /[\mathrm{OH}]$ ratios, indicated that the $T_{\mathrm{g}} \mathrm{s}$ of the corresponding crosslinked materials followed the same trend as that of the amounts of insoluble fractions, as

\section{Table 2}

Proportions of soluble and insoluble products and $T_{\mathrm{g}}$ of the insoluble fractions of suberin-based polyurethanes prepared with various polyfunctional isocyanates and $[\mathrm{NCO}]_{0} /[\mathrm{OH}]_{0}=1$

\begin{tabular}{lllc}
\hline Isocyanate & $\begin{array}{l}\text { Soluble fraction } \\
(\%)\end{array}$ & $\begin{array}{l}\text { Insoluble frac- } \\
\text { tion }(\%)\end{array}$ & $T_{\mathrm{g}}\left({ }^{\circ} \mathrm{C}\right)$ \\
\hline TDI-II & 27.7 & 71.5 & 105 \\
MDI-2.0 & 29.0 & 70.3 & 98 \\
MDI-2.7 & 25.1 & 73.9 & 97 \\
HMDI & 28.6 & 71.0 & 25 \\
\hline
\end{tabular}

shown in Table 1, and again the highest value of $T_{\mathrm{g}}$ was reached with the stoichiometric conditions. Fig. 5 shows the DSC thermogram of this suberin-MDI-2.0 polyurethane before extraction and those of its soluble and insoluble fractions. The $T_{\mathrm{g}}$ of the whole product before extraction $\left(60^{\circ} \mathrm{C}\right)$ was much lower than that corresponding to the insoluble crosslinked fraction $\left(98^{\circ} \mathrm{C}\right)$ because of the plasticizing effect of the extracted soluble product, made up of linear and branched chains, which indeed had a $T_{\mathrm{g}}$ of only $42^{\circ} \mathrm{C}$.

The reaction of suberin with the other multifunctional isocyanates showed that the syntheses behaved in the same way as that encountered with MDI-2.0. The amount of insoluble products (Table 2) was similar for all the diisocyanates used, whereas MDI-2.7 gave a somewhat higher percentage of crosslinking because of its higher functionality. The FTIR and ${ }^{1} \mathrm{H}$ NMR spectra of 


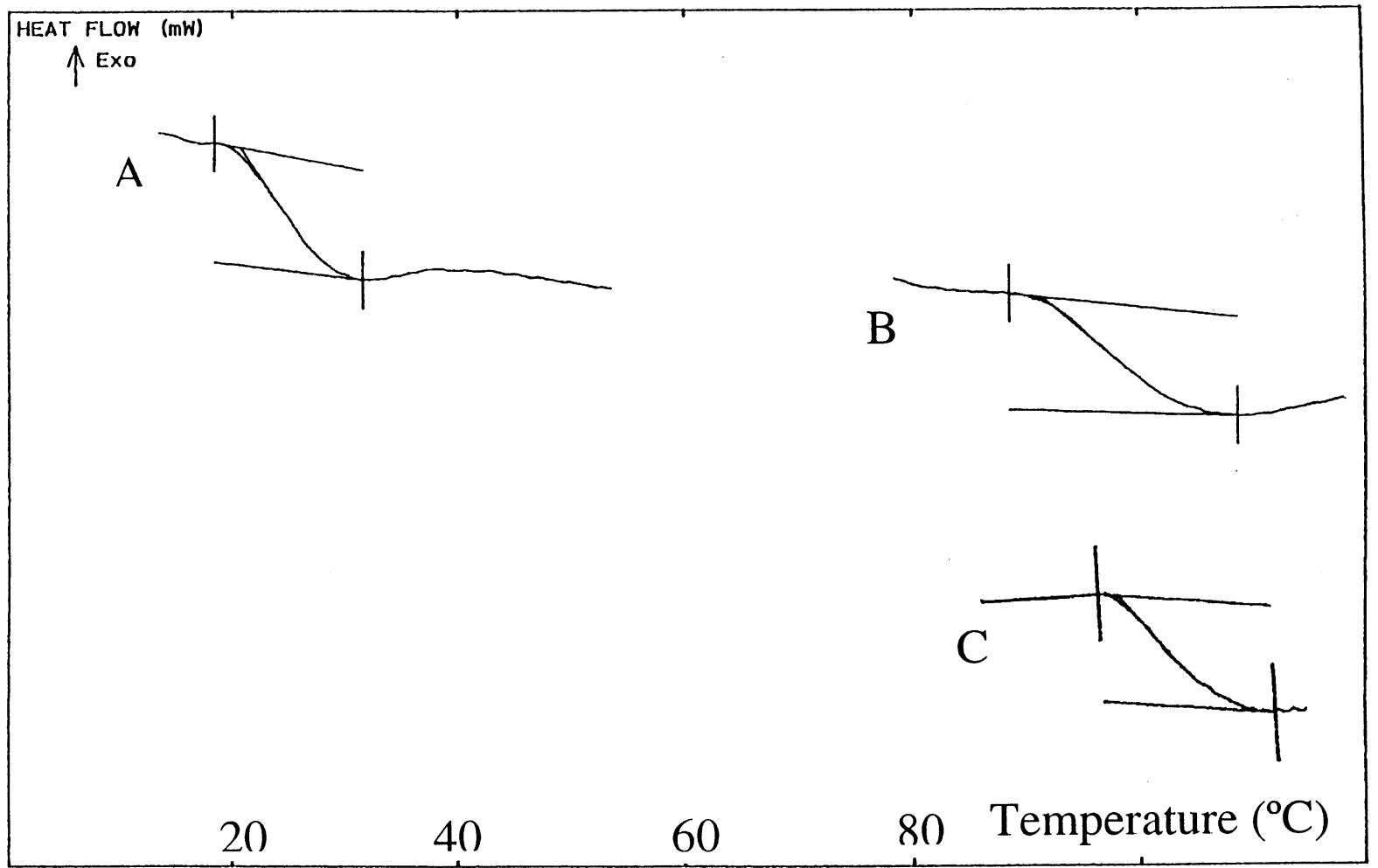

Fig. 6. DSC thermograms of suberin-based polyurethanes prepared with $[\mathrm{NCO}]_{0} /[\mathrm{OH}]_{0}=1$; (A) suberin-HMDI; (B) suberin-MDI2.7 ; (C) suberin-MDI-2.0.

these polyurethanes displayed the same peaks as those detected in the suberin-phenyl-urethane and suberin-MDI-2.0 polyurethane spectra, except for the specific peaks associated with the moieties bearing the NCO functions. Thus, for suberinHMDI polyurethanes, the peak corresponding to the hexamethylene moiety at $2960 \mathrm{~cm}^{-1}$ reinforced that of the aliphatic protons arising from long chains of suberin, whereas for the suberinaromatic counterparts, each spectrum bore the presence of the specific peaks related to the correspondingly substituted aromatic rings.

It was systematically observed that the relative intensity of the aliphatic peaks in the spectra of the soluble products was higher than that arising from the spectra corresponding to the insoluble counterparts. This confirms that the soluble fractions of all these polyurethanes were mainly made up of the suberin macromonomer bearing a low content of $\mathrm{OH}$ groups.
Table 2 also gives the glass transition temperature of the insoluble products corresponding to the various suberin-based polyurethanes prepared under stoichiometric conditions. The glass transition temperature of an amorphous polymer is an excellent probe of its chain stiffness. The presence of flexible aliphatic segments in HMDI was thus accompanied by a logical decrease in the $T_{\mathrm{g}}$ of the corresponding crosslinked polyurethane $\left(25^{\circ} \mathrm{C}\right)$ compared with those of the aromatic-based counterparts (Fig. 6).

The thermal degradation of these polymers was investigated by TGA under nitrogen. Two features can be noticed in the typical thermograms shown in Fig. 7, namely: (i) the onset of weight loss between 150 and $175^{\circ} \mathrm{C}$, which is usually attributed to the thermally induced reverse reaction of urethane moieties giving back hydroxy and isocyanate functions (the higher thermal stability of aliphatic urethanes with respect to aro- 


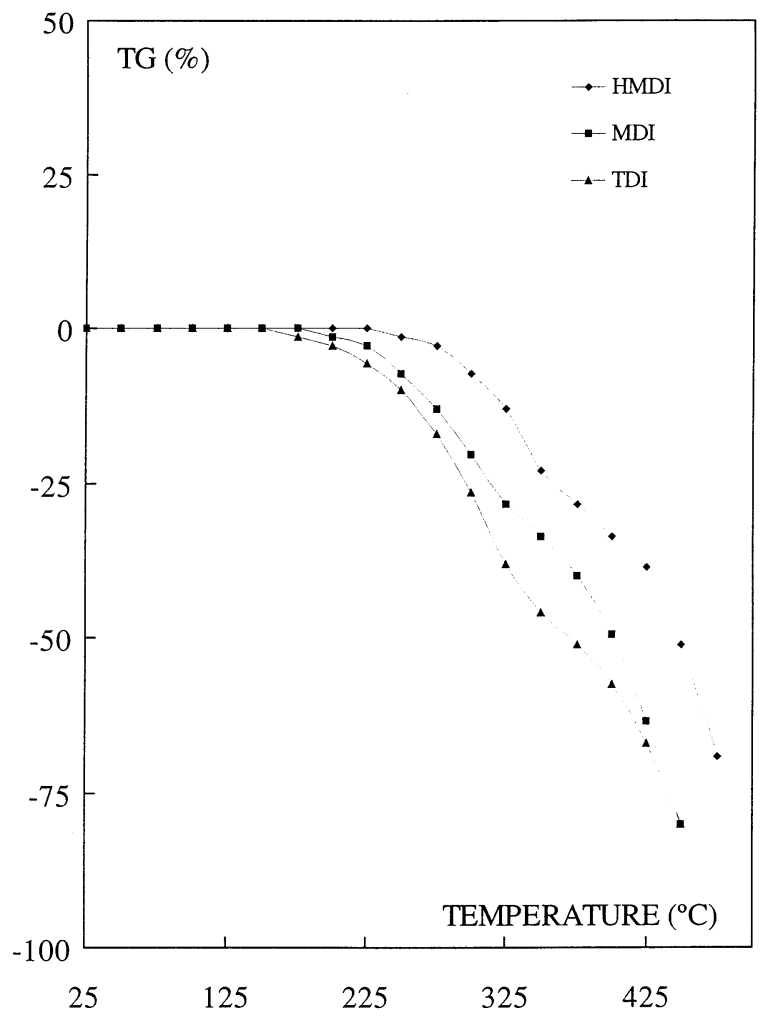

Fig. 7. TGA thermograms of suberin-based polyurethanes prepared with $[\mathrm{NCO}]_{0} /[\mathrm{OH}]_{0}=1 ;$ (A) suberin-HMDI; (B) suberin-MDI-2.7; (C) suberin-TDI-II.

matic ones is well documented (Orzesko and Kolbrecki, 1980)); and (ii) the residue at $400^{\circ} \mathrm{C}$ which was found to be 66,50 , and $42 \%$ for suberin-HMDI, suberin-MDI-2.7 and suberinTDI-II, respectively. This trend, which shows that aliphatic polyurethanes leave a higher residue than aromatic ones, is in disagreement with those reported in the literature (Boufi et al., 1993). We have no explanation for this discrepancy. It is worth emphasizing that the relatively modest resistance to heating of the suberin-based polyurethanes does not represent a handicap with respect to their possible applications, because it is in fact a feature shared by all polyurethanes, intrinsic to the $-\mathrm{NH}-\mathrm{CO}-\mathrm{O}-$ moiety.

\section{Conclusion}

The suberin-based polyurethanes obtained in this investigation justify the general conclusion that this new family of polymers is a respectable addition to those already known, viz. aliphatic, aromatic and furanic. These materials contained both thermoplastic and thermoset topologies because of the variable number of $\mathrm{OH}$ groups borne by the suberin macromonomers. Their glass transition temperature could be modulated by using the adequate isocyanate, in accordance with the applications envisaged. The main interest of these materials resides in the fact that they are obtained from a renewable by-product, which is usually destroyed by combustion for energy recovery.

\section{Acknowledgements}

The authors wish to thank the French-Portuguese Scientific Cooperation Programme and JNICT Portugal for financial support and the Champcork Company for the kind gift of cork powder.

\section{References}

Boufi, S., Belgacem, M.N., Quillerou, J., Gandini, A., 1993. Urethanes and polyurethanes bearing furan moieties. 4. Synthesis, kinetics and characterization of linear polymers. Macromolecules 26, 6706-6717.

Carvalho, J.S., 1968. A química da cortiça. Bol. Junta Nac. Cortiça-Lisb. 357, 3-11.

Cordeiro, N., Gandini, A., Pascoal Neto, C., Belgacem, M.N., 1995. Surface properties of cork by IGC. J. Colloid Interface Sci. 174, 246-249.

Cordeiro, N., Aurenty, P., Belgacem, M.N., Gandini, A., Pascoal Neto, C., 1997a. Surface properties of suberin. J. Colloid Interface Sci. 187, 498-508.

Cordeiro, N., Belgacem, M.N., Pascoal Neto, C., Gandini, A., 1997b. Urethanes and polyurethanes from suberin. 1. Kinetic study. Ind. Crops Prod. 6, 163-167.

Cordeiro, N., Belgacem, M.N., Silvestre, A.J.D., Neto, C.P., Gandini, A., 1998a. Cork suberin as a new source of chemicals. 1. Isolation and chemical characterization of its composition. Int. J. Biol. Macromol. 22, 71-78.

Cordeiro, N., Belgacem, M.N., Gandini, A., Pascoal Neto, C., 1998b. Cork suberin as a new source of chemicals. 2. Crystallinity, thermal and rheological properties. Biores. Technol. 63 (2), 153-158.

Gandini, A., 1992. Polymers from renewable resources. In: Comprehensive Polymer Science, First suppl. Pergamon Press, Oxford, pp. 527-573. 
Guillemonat, A., 1960. Progrès récents dans la étude de la constitution chimique du liège. Ann. Fac. Sci. 30, 4354.

Holloway, P.J., 1972. The composition of suberin from the corks of Quercus suber L. and Betula pendula R. Chem. Phys. Lipids 9, 158-170.

Marques, A.V., Pereira, H., 1987. On the determination of suberin and other structural components in cork Quercus suber L. An. Instit. Super. Agron.-Lisb. 42, 321-335.

Orzesko, A., Kolbrecki, A., 1980. Thermal degradation of polyurethanes. Model compounds. J. Appl. Polym. Sci. 25, 2969-2973.

Pereira, H., 1984. Composição Química da cortiça virgem e da cortiça de reprodução amadia do Quercus suber L. Bol. Instit. Prod. Florestais 550, 237-240.

Pereira, H., 1988. Chemical composition and variability of cork from Quercus suber L. Wood Sci. Technol. 22, 211-218.

Yanes, J.F., Sanchez, R., 1961. Preparacion de polimeros a partir de acidos del corcho, Anal. Fís. Quim., Tomo LVIIIB, 541-552. 